\title{
The Application and Research of Dynamic Control the Flood Limited Water Level of Wuqiangxi Reservoir
}

\author{
Xin $\mathrm{Wu}^{1, \mathrm{a}}$, Ping Zhong ${ }^{1}$ \\ WULING POWER CORPORATION LTD., Changsha, China
}

\begin{abstract}
This paper briefly introduces the method, content and approval process of the dynamic control of the flood limited level in Wuqiangxi reservoir, and summarizes the benefits since the implementation of dynamic control. The relevant research results of this paper can be used as reference for production technology management personnel.
\end{abstract}

\section{Wuqiangxi reservoir}

Wuqiangxi Hydropower Plant is located in Yuanling County, downstream of Yuanshui, Hunan, $300 \mathrm{~km}$ away from Changsha City. With the total installed capacity of 1.2 million $\mathrm{kW}$, the power plant is the largest hydropower plant in Hunan Province. The reservoir control basin area is $83800 \mathrm{~km}^{2}$, accounting for $93 \%$ of the total basin area, and the average annual runoff is 63.1 billion $\mathrm{m}^{3}$. The normal water storage level of the reservoir is $108 \mathrm{~m}$, and the storage capacity is 2.02 billion $\mathrm{m}^{3}$. It is a seasonally regulated reservoir. The flood limited water level is $98 \mathrm{~m}$, and the flood control high water level is $108 \mathrm{~m}$. The corresponding flood control capacity is 1.36 billion $\mathrm{m}^{3}$. Designed in conjunction with the upstream Fengtan reservoir for flood control, the flood control standard for Yuanshui can be increased from 5-year to 20-year.

\section{Research Background}

At the beginning of the operation of Wuqiangxi reservoir, the actual implementation of the flood limited water level changed greatly from April to September. From 1995 to 1998, it was 98m; In 1999, it reduced to 96m; And in 2000, it reduced to $94 \mathrm{~m}$. Lowered the limited water level has a great impact on the comprehensive benefits of engineering, such as power generation, shipping and water supply and so on. During the period 2000 to 2001, Wuqiangxi reservoir was in the low water period, and the power supply of Hunan Province changed from relative surplus to relative shortage. How to make better use of the comprehensive utilization benefits of Wuqiangxi reservoir for power generation and flood control, rationally using water resources and promoting scientific dispatch of reservoirs are highly valued by the Hunan Province government.

At the end of 2001, the Hunan Flood Control and Drought Relief Headquarters organized the work which was "Design and Application Research on the Limit Water
Level of Wuqiangxi Reservoir". In April 2002, the research outline was approved by the National Flood Control and Drought Relief Headquarters. In May, the Provincial Flood Control and Drought Relief Headquarters assigned research tasks to six units including design, hydrology, meteorology and power industry departments, etc. In September 2003, the preliminary draft of the report passed the expert review. In March 2004, the "Report on the Design and Application of the Limit Water Level of Wuqiangxi Reservoir" ${ }^{[1]}$ was officially formed. In May 2005, it was approved by the National Flood Control and Drought Relief Headquarters. In March 2006, based on the research report, the "Wuqiangxi Reservoir Flood Dispatch Plan" was prepared and approved by the Yangtze River Flood Control and Drought Relief Headquarter, and was officially approved in June.

\section{Main research contents and conclusions}

The research is divided into nine parts :Analysis of Safety Discharges in the Lower Reaches of the Yuanshui, Analysis of the Current Flood Control Effect of Wuqiangxi reservoir, Flood Forecasting Technology and Evaluation, Meteorological Technology Application Evaluation, Analysis of the Staged Flood of Wuqiangxi, Study on the Control Scheme of Limited Water Level Staging, Study on Dynamic Control Scheme of Flood Water Level in Flood Season, Simulation Analysis of Actual Flood Simulation and Study on Scheduling Rules of Wuqiangxi reservoir, the dynamic control scheme for the limit water level of Wuqiangxi reservoir was comprehensively formulated. The main research conclusions are as follows:

\subsection{The safety discharge of downstream river}

The safety discharge of the downstream channel of the Yuanshui is the basis for the flood control planning and 
flood dispatching of the Wuqiangxi reservoir. There are 13 key dikes in the downstream area. According to the longitudinal and cross-section data measured by the river channel, the constant flow surface line under different water levels of the Dongting Lake is calculated. Through comprehensive analysis, after the second phase of the Dongting Lake project, the safety discharge of the downstream area is $23000 \sim 26600 \mathrm{~m}^{3} / \mathrm{s}$, there is a significant increase in the downstream safety discharge compared with $20000 \mathrm{~m}^{3} / \mathrm{s}$ which was confined in the preliminary design stage of the Wuqiangxi project.

At present, with the Three Gorges Project as the representative, the mega-reservoir group in the middle and upper reaches of the Yangtze River has been completed. The Yangtze River Flood Control and Drought Relief Headquarters has organized the implementation of joint flood control dispatching, which will try to stagger the flood in master stream of Yangtze River and the Dongting Lake, and avoid the flood flow obstructing at the junction of downstream of Yuanshui and Dongting Lake ${ }^{[1]}$. In July 2017, the Wuqiangxi reservoir experienced an exceeding standard flood. The actual dispatch indicated that when Wuqiangxi reservior was discharged $22000 \mathrm{~m}^{3} / \mathrm{s}$, the safety of the downstream of Yuanshui was guaranteed.

\subsection{The current capacity of flood control of Wuqiangxi reservoir}

During the engineering design stage, due to factors such as immigration and flooding in the reservoir area. The flood control high water level and normal water level final approved by the state are all $108 \mathrm{~m}$, the flood control capacity is small and cannot take the mission of flood control of downstream independently. It is far from the national plan that the standard of flood control is 50-year in downstream and 100-year in Changde city.

The power generation, flood discharge, ship locks, other buildings and their supporting electromechanical equipment and metal structures of Wuqiangxi project are designed and arranged according to the reservoir water level of $110 \mathrm{~m}$. The project has $110 \mathrm{~m}$ normal operating conditions.

\subsection{The characteristics of stage flood}

According to the historical hydrological and meteorological statistics, the flood season of Wuqiangxi reservoir shows obvious staging characteristics. The flood season can be divided into five periods: April, May, JuneJuly, August and September. According to the analysis results of the staged flood frequency, from June to July is the largest flood period of the year, and the design flood is consistent with the annual maximum design flood. The flood once in 100 years in May is only equivalent to the design flood in 5 years. The flood once in 100 years in August is less than the design flood in 5 years.

The design analysis of staged flood is the basis for formulating the dynamic control scheme of the limit water level of Wuqiangxi reservoir. The results have important guiding significance for the strategy of actual dispatching.

\subsection{The conditions of dynamic water level}

Firstly, the forecast of major rainfall process in meteorological forecast has high credibility, which has guiding significance for the macro-control of reservoir water level ${ }^{[2]}$. Secondly, the accuracy of most floods during the effective forecast period of 15 to 18 hours and the time for predicting the pre-discharge of the reservoir is guaranteed. Thirdly, the Wuqiangxi reservoir has a strong pre-discharge capacity. During the 12-hour forecast period, the pre-discharge can reduce the level by $4.4 \mathrm{~m}$ at least.

In recent years, the meteorological forecasting technology has developed rapidly. The accuracy of qualitative forecasting for the 7-day forecast period is more than $75 \%$, and the accuracy of no-rain forecasting is over $90 \%$. At present, when the rainstorm center is concentrated in the upstream of Yuanshui, the forecast period of Wuqiangxi reservoir is 1 to 2 days, and the average forecasting accuracy is about $90 \%$, which provides a reliable technical guarantee for the dynamic control of water level.

\subsection{The scheme of dynamic control the limited water level}

In April and September, there is no limited water level. In May, the limited water level is controlled to $102 \mathrm{~m}$. During June to July, the limited water level is controlled to $98 \mathrm{~m}$. In August, the limited water level is controlled to $102 \mathrm{~m}-$ $108 \mathrm{~m}$.

In the actual flood control operation of Wuqiangxi, the concept of dynamic control is fully embodied. Generally, before the flood rises or at the beginning of the flood, the reservoir water level will be controlled near the flood limit water level, and reduce the starting water level of

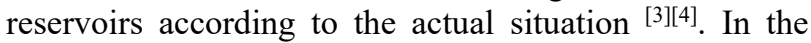
stage of intercepting the flooding, according to the later weather conditions, the reservoir can operate beyond the limited water level $2 \mathrm{~m}$ to $4 \mathrm{~m}$.

\section{Application results and benefits}

The dynamic control scheme for the limited water level of the Wuqiangxi reservoir began trial operation in the flood season in 2004. In the actual reservoir dispatching operation, Remote Dispatching Center rolling provided flood forecasting results and flood dispatching proposals to Hunan Provincial Flood Control and Drought Relief Headquarters. Under the scientific dispatch of Hunan Provincial Flood Control and Drought Relief Headquarters, good flood control benefits and power generation benefits have been achieved after 15 years of flood control dispatching practice.

\subsection{Flood control dispatching of Wuqiangxi reservoir over the years}

From 2004 to 2018 , there were 81 flood events with a peak flow of more than $6000 \mathrm{~m}^{3} / \mathrm{s}$ occurred in Wuqiangxi reservoir, of which 72 were small and medium-sized floods (flood peak flow between $6000 \mathrm{~m}^{3} / \mathrm{s}$ to $20000 \mathrm{~m}^{3} / \mathrm{s}$ ), 
accounting for $88.9 \%$; and 9 were large floods (peak flow $>20000 \mathrm{~m}^{3} / \mathrm{s}$ ), accounting for $11.1 \%$. During the past 15 years, the magnitude of the annual maximum floods has been quite different. The flood of the Wuqiangxi reservoir in 2017 exceeded the design flood standard of 20 years. The flood in 2011 was the smallest annual flood since the construction of the Wuqiang reservoir.

The Wuqiangxi reservoir has a great effect on flood peak interception for short time. The peak flow of the largest flood in the past years is above $7500 \mathrm{~m}^{3} / \mathrm{s}$, the peak clipping rate is above $25 \%$, and reduce of the water level of the downstream is more than $1.5 \mathrm{~m}$.

The peak discharge of Wuqiangxi reservoir was 32400 $\mathrm{m}^{3} / \mathrm{s}$ (Over 20-year) in 2017. Wuqiangxi reservoir released 966 million $\mathrm{m}^{3}$ water before the flood, and intercepted the flood to 1.547 billion $\mathrm{m}^{3}$.Wuqiangxi reservoir maximum outflow was $22500 \mathrm{~m}^{3} / \mathrm{s}$, which clipped the peak by $9900 \mathrm{~m}^{3} / \mathrm{s}$ and delayed the flood peak of downstream for 30 hours.

Through the joint flood control dispatching of the Yuanshui cascade reservoirs, a total of 3 billion $\mathrm{m}^{3}$ of floods were intercepted and the downstream water level was reduced by $2 \mathrm{~m}$ to $2.5 \mathrm{~m}$. It ensured flood control safety in the downstream reaches of Wuqiangxi reservoir. According to preliminary reduction analysis, if there was no joint dispatching of Sanbanxi, Baishi and Tuokou reservoirs, the flood peak flow of Wuqiangxi reservoir would increase to over $38000 \mathrm{~m}^{3} / \mathrm{s}$, and the maximum three-day flood volume would increase to 7.41 billion $\mathrm{m}^{3}$. The flood peak and the three -day flood volume would both more than 30-year. The flood similar to the 1996 would be re-emerged, and severe flood damage would be suffered in the downstream area.

\subsection{Dynamic control of power generation efficiency}

According to statistics, 14.1 billion $\mathrm{m}^{3}$ abandonment water has reduced, and 1.988 billion $\mathrm{kWh}$ power generation has increased, and $¥ 550$ million benefits has increased since implemented the dynamic control of the limited water level.

Table1. Benefit statistics of dynamic control of flood limit water level in Wuqiangxi Reservoir

\begin{tabular}{|c|c|c|c|}
\hline Year & $\begin{array}{c}\text { wbandonment } \\
\text { water utilized } \\
\text { (million } \mathbf{~ m}^{\mathbf{}} \text { ) }\end{array}$ & $\begin{array}{c}\text { Exceeding } \\
\text { power } \\
\text { generation } \\
\text { (million } \mathbf{k W} \cdot \mathbf{h} \text { ) }\end{array}$ & $\begin{array}{c}\text { Exceeding } \\
\text { income } \\
\text { (million } \\
\text { RMB) }\end{array}$ \\
\hline 2004 & 1590 & 253.6 & 65.9 \\
\hline 2005 & 89.6 & 12.7 & 3.3 \\
\hline 2006 & 581.9 & 77.4 & 20.1 \\
\hline 2007 & 1493.9 & 213.1 & 55.4 \\
\hline 2008 & 225.8 & 31.8 & 8.3 \\
\hline 2009 & 717 & 120.5 & 31.3 \\
\hline 2010 & 770 & 142.2 & 37 \\
\hline 2011 & 523 & 85.6 & 24.5 \\
\hline 2012 & 1370.8 & 152.3 & 43.6 \\
\hline
\end{tabular}

\begin{tabular}{|c|c|c|c|}
2013 & 937.2 & 106.5 & 30.5 \\
\hline 2014 & 1050 & 136.8 & 39.1 \\
\hline 2015 & 1437.5 & 259.3 & 77.8 \\
\hline 2016 & 1453.2 & 185.7 & 55.7 \\
\hline 2017 & 1683 & 187 & 52.4 \\
\hline 2018 & 178 & 23.5 & 6.6 \\
\hline $\begin{array}{c}\text { In } \\
\text { Total }\end{array}$ & 14100.9 & 1988 & 551.5 \\
\hline
\end{tabular}

\section{Several cognitions}

(1) The literature [5] is comprehensive in research, scientific in methodology, conclusions are in line with reality, and the program is highly maneuverable, reflecting the scientific concept of flood resource utilization.

(2) The dynamic control scheme and technical support system for the limited water level of Wuqiangxi reservoir have been completed. In the real-time flood control dispatching decision, it should be dominated by technical analysis, and under the premise of ensuring the safety, the comprehensive utilization benefits such as flood control and power generation can be fully exerted.

(3) In the middle and late July, the Yuanshui basin is more prone to the end of the rainy season. With the transition of the flood to drought, the meteorological situation at the end of the rainy season should be organized in advance to promote development of water storage at the end of flood season.

\section{References}

1. D.Y.Liu, G.Q.Ji. J.Hydroelectric.Eng, 6(2009).

2. R.T.Qiu,B.D.Wang,H.C.Zhou.Adv.Water.Sci,1(2004).

3. Y.P.Zhang, M.Li, B.D.Wang, H.C.Zhou etc. J. Hydroelectric. Eng, 6(2010).

4. J.Y.Deng, Q.Yu, L.Ma, K.X.Liu. Wate.Rsrc \&Hdropower.NE.CHN, 8(2018).

5. China. Hunan Provincial Flood Control and Drought Relief Headquarters Department. Report on the Design and Application of the Limit Water Level of Wuqiangxi Reservoir. Changsha: Hunan Provincial Flood Control and Drought Relief Headquarters Department, 2004. 